\title{
The role of segment polarity genes during Drosophila neurogenesis
}

\author{
Nipam H. Patel, ${ }^{1}$ Brenda Schafer, ${ }^{2}$ Corey S. Goodman, ${ }^{1}$ and Robert Holmgren ${ }^{2}$ \\ ${ }^{1}$ Howard Hughes Medical Institute, Department of Biochemistry, University of California-Berkeley, Berkeley, California \\ $94720 \mathrm{USA}_{i}{ }^{2}$ Department of Biochemistry, Molecular Biology, and Cell Biology, Northwestern University, Evanston, Illinois \\ 60208 USA
}

\begin{abstract}
Segment polarity genes in Drosophila are required for the proper formation of epidermal pattern within each segment. Here we show that certain segment polarity genes are also critical for the determination of specific neuronal identities in the developing central nervous system (CNS) of the Drosophila embryo. For several mutants, however, the pattem defects do not simply parallel their cuticular phenotypes. In fused, armadillo, and cubitus interruptus Dominant mutants, much of the CNS appears relatively normal. In hedgehog mutants, the CNS is highly disorganized, but this disruption may occur secondary to the initial events of neurogenesis. The specific cellular defects in patched mutants suggests that this gene specifies a subset of neuroblasts and neural progeny underlying the region of epidermal pattern defect. gooseberry mutants display a complex series of alterations in neuronal identity both underlying and outside of the region of epidermal modification.

Neuronal identities of a set of cells along the midline appear to be changed in Cell mutants. The phenotype of wingless mutants is the most restricted and may be due to improper communication between sibling neurons. Thus, in addition to their functions in epidermal pattern formation, at least four of the segment polarity genes (gooseberry, patched, Cell, and wingless) appear to have specific roles in the control of cell fates during neurogenesis.
\end{abstract}

[Key Words: Neurogenesis; segment polarity genes; pattern formation; neuronal determination; cell fate]

Received December 27, 1988; revised version accepted March 13, 1989.

In Drosophila, the process of neurogenesis results in the production of a highly ordered array of neurons within the central nervous system (CNS). In each hemisegment in the embryo, $\sim 250$ neurons are generated, many of which can be uniquely identified based on the location of their cell bodies and axons and by their expression of particular nuclear proteins, cell-surface proteins, and neurotransmitters. Much is known about the genes required for the initial neurogenic decision between neuronal and nonneuronal fates (e.g., Artanvanis-Tsakonas 1988, Campos-Ortega 1988), but we are just beginning to identify genes involved in giving unique identities to the individual neuronal precursor cells and their neuronal progeny.

During insect neurogenesis, a highly stereotyped pattern of neuronal precursor cells, called neuroblasts (NBs), delaminates from a sheet of undifferentiated ectoderm within the ventral neuroepithelium. Depending on the insect species, each hemisegment contains from 25 to $30 \mathrm{NBs}$ (Bate 1976; Hartenstein and Campos-Ortega 1984; Doe and Goodman 1985a; Doe et al. 1988b|. Each NB undergoes asymmetric cleavages to generate a string of progeny called ganglion mother cells (GMCs); each GMC then divides once to produce a pair of neurons. Laser ablation experiments (Doe and Goodman 1985b) indicate that any neuroepithelial cell can become a NB, but once a NB forms, it inhibits its neighbors from entering this neuronal differentiation pathway. The position of a NB within the NB array gives it an individual identity. This identity is manifested by the generation of a characteristic family of GMCs through an invariant cell lineage. Each GMC generates a pair of equivalent sibling neurons; each neuron's final identity is dependent on its GMC of origin and interactions with its sibling (Doe and Goodman 1985b; Kuwada and Goodman 1985).

Many zygotic genes have been identified that control the decision of cells to become neural or nonneural le.g., Artavanis-Tsakonas 1988; Campos-Ortega 1988), but only recently have genes been identified that are involved in the positional determination of NBs, the lineal determination of their GMC progeny, or the determination by local cell interactions of the final pairs of sibling neurons. Thus far, many of the candidates for genes involved in neuronal determination in the developing CNS come from a group of well-studied genes that are better known for the role they play during segmentation.

Nüsslein-Volhard, Wieschaus, and their colleagues (Nüsslein-Volhard and Wieschaus 1980; Jürgens et al. 1984; Nüsslein-Volhard et al. 1984; Wieschaus et al. 1984) discovered three classes of segmentation genesgap, pair-rule, and segment polarity - which are required 
for the proper division of the embryo into segmental units. These genes appear to act in a hierarchical manner as they divide the embryo sequentially into smaller units down to the level of segments and parts of segments (for review, see Akam 1987; Ingham 1988). The last genes to act are the segment polarity genes, which are required for the formation of the correct pattern of structures within each segment. Mutations in the segment polarity genes lead to the elimination of stnuctures within each segment, and in certain cases, to mirrorimage duplications of the remaining structures.

The gap and pair-rule genes are expressed by the cellular blastoderm stage (Akam 1987); their segmentation functions largely have been performed before neurogenesis begins shortly after gastrulation. An interesting discovery over the past several years was that some of the pair-rule genes are reexpressed during neurogenesis in a different pattern than during segmentation /Carroll and Scott 1985; Hiromi et al. 1985; MacDonald et al. 1986; Frasch et al. 1987). In contrast to their initial pairrule expression, many of these genes are reexpressed during neurogenesis in a specific subset of neuronal precursor cells and neurons in a segmentally repeated pattern. These observations led to the hypothesis that the same regulatory genes that initially function to control cell fate during segmentation may later be used to control cell fate during neurogenesis. This hypothesis was tested experimentally and confirmed for two of the pairrule genes: fushi tarazu (ftz) and even-skipped (eve) (Doe et al. 1988a,b).

In this study, we chose to examine the potential role of a second class of segmentation genes, the segment polarity genes, in controlling cell fate during neurogenesis. The segmentally repeated defects in the epidermis of segment polarity mutants led us to wonder whether these genes might also be involved in the patterning of the underlying CNS. Moreover, some of the segment polarity genes are active before and during the period of neurogenesis (Nüsslein-Volhard and Wieschaus 1980; Baker 1987, 1988; Martinez-Arias et al. 1988), and some are known to be expressed within the neurogenic region (Bopp et al. 1986; Baumgartner et al. 1987; Cote et al. 1987). Thus, just as segment polarity genes divide each segment of the ectoderm into specific regions, so they might also divide the underlying array of NBs into similar regions and thereby impart positional information to the rows and columns of NBs. If this were the case, we would expect to see regional pattern defects in the nervous system that are homologous to the defects seen in the cuticle.

On the other hand, if the segment polarity genes have additional roles in controlling cell fate during neurogenesis apart from their regional specification within each segment (perhaps by specifying particular GMCs or neuronal progeny within individual NB lineages), we might expect to see pattern defects of a more specific nature in the developing CNS that do not simply reflect the defects seen in the cuticle.

In this study we used six different antibodies to probe the pattern of identified neurons in the developing nervous system of segment polarity mutants, giving particular attention to the developing CNS. Our results suggest that mutations in the segment polarity genes cause pattern defects in the peripheral nervous system (PNS) but that mutations in only a subset of the segment polarity genes cause clear alterations in the CNS. The CNS of gooseberry $(g s b)$, patched $\langle p t c)$, Cell $(C e)$, and wingless $|w g|$ mutants show specific cellular defects in a subset of neurons, suggesting that these four genes also function in specifying the fate of a specific subset of neurons during neurogenesis.

\section{Results}

Phenotypes of segment polarity mutants

Six segment polarity mutants were initially described by Nüsslein-Volhard and Wieschaus (1980). Additional mutants in this class have been identified, and now $>10$ segment polarity genes have been studied to date (Jürgens et al. 1984; Nüsslein-Volhard et al. 1984; Wieschaus et al. 1984; Orenic et al. 1987; Perrimon and Mahowald 1987). We have examined the development of the nervous system in eight segment polarity mutants, cubitus interruptus Dominant ( $\left.\mathrm{Ci}^{\mathrm{D}}\right), \mathrm{wg}, \mathrm{gsb}$, fused (fu), ptc, hedgehog (hh) (Nüsslein-Volhard and Wieschaus 1980), armadillo (arm) (Wieschaus et al. 1984), and Ce (Orenic et al. 1987). Although the phenotype of each segment polarity mutant is unique, the mutants can be placed into classes according to the nature of their pattern defects.

The most extreme defects are seen in the mutants $w g$ and $h h$. On the ventral surface of these mutants, the posterior half and the anterior margin of the adjacent segments are deleted. This results in an embryo that is much smaller than normal and is covered with a disorganized array of denticles on the ventral surface.

In the mutant $C e$, the pattern defects on the ventral surface also eliminate the posterior half of each segment and extend into the anterior margin of the adjacent segment. In this mutant, the pattern defects are not as extreme as the previous group, and the segmental repeats can be clearly distinguished. The denticle belts that cover the ventral surface generally have normal polarity except along the posterior margin where the polarity is reversed.

In $f u, c i^{D}, g s b$, and arm mutants, the posterior half of each segment on the ventral surface is replaced with a mirror-image duplication of the anterior half of the segment. This results in the elimination of the clear cuticle from each segment and a duplication of the denticle belt.

In mutants of $p t c$, structures in the middle of the segment are eliminated and replaced with a mirror-image duplication of the anterior and posterior margins of the segment.

The phenotypes described above are those caused by the strongest mutant alleles. In our characterization of nervous systems from segment polarity mutants, we also have used the strongest alleles, but it is still possible that they are not null mutations. This is certainly a 
consideration for the deficiency trans-heterozygous embryos used to analyze the gs $b$ mutation, as a small amount of transcript is still found from the $g s b-p$ gene of the complex (Cote et al. 1987). A second problem is maternal contribution of wild-type product to the egg. In the case of the arm gene, it has been shown that there is a maternal contribution of $\mathrm{arm}^{+}$product to the egg. Unfortunately, it is not possible to eliminate the maternal contribution because the $\mathrm{arm}^{+}$product is required for oogenesis (Wieschaus and Noell 1986). There is also a maternal contribution of $\mathrm{fu}^{+}$product to the egg, but the $\mathrm{fu}^{+}$function can be eliminated in the germ line of the mother (Lindsley and Grell 1968). The mother does not contribute $\mathrm{wg}^{+}$(Baker 1987), $\mathrm{Ce}^{+}, \mathrm{ci}^{D+}$ (Orenic et al. 1987), gsb (Bopp et al. 1986; Cote et al. 1987), and ptc ${ }^{+}$ (P. Lawrence, pers. comm.) product to the developing egg, and the maternal contribution of $h h^{+}$product has not been tested.

\section{Antibody assays for specific neurons}

To study patterning in the developing nervous system in segment polarity mutants, we used a series of antibodies that allow us to examine both the overall structure of the nervous system and the location and identity of particular neurons. In studies of the PNS, we used the SOXII monoclonal antibody (mAb), which stains all sensory neurons (Goodman et al. 1984). In the CNS, we used six antibody probes: (1) the anti-horseradish peroxidase (anti-HRP) antibody, which recognizes a neural-specific carbohydrate moiety expressed on the surface of all neurons and axons (Jan and Jan 1982; Snow et al. 1987); (2) the $2 \mathrm{D} 5 \mathrm{mAb}$, which recognizes a surface glycoprotein called fasciclin III (Patel et al. 1987), which is expressed on the surface on a small subset of neuronal cell bodies and axon pathways; (3) the SOXII mAb, which recognizes a subset of motor neurons in the CNS (Goodman et al. 1984); (4) an anti-serotonin (5-HT) antibody, which recognizes a pair of neurons in each hemisegment that expresses this neurotransmitter (Valles and White 1985); (5) an anti-eve antibody, which recognizes a small number of neuronal cell bodies expressing this nuclear protein (Frasch et al. 1987; Doe et al. 1988a); and $(6)$ a monoclonal antibody against engrailed (en), which recognizes a different set of neuronal nuclei (DiNardo et al. 1985; N.H. Patel et al., in prep). The anti-HRP antibody, SOXII $\mathrm{mAb}$, and the anti-serotonin antibody recognize antigens that are not expressed by neurons in the CNS until germ-band retraction. The 2D5 mAb, anti-en mAb, and anti-eve antibody, on the other hand, have the advantage that some neurons express these antigens before germ-band shortening and, therefore, before some of the later morphological deformation that occurs during germ-band retraction in some of the segment polarity mutants.

\section{PNS}

We examined the overall structure of the PNS in $w g, h h$,
$C e, f u, c i^{D}, g s b, a r m$, and ptc mutants. We see pattern defects in all mutants, and the defects seem to parallel the alterations seen in the cuticle (data not shown).

\section{CNS}

We examined the CNS in $w g, h h, C e, f u, c i^{D}, g s b, a r m$, and ptc mutants. In $f u, c i^{D}$, and arm mutants, we do not find consistent alterations in neuronal cell fate with any of the probes used. Many of the distortions seen in the nervous system of these mutants are probably due to morphological distortions that occur during or after germ-band shortening. The initial neuron pattern appears normal in $h h$, but severe disruptions occur during germ-band shortening; this may be due to widespread cell death within the CNS. In wg mutants, the only identifiable cell we find consistently altered is the RP2 neuron. $C e$ mutants reveal a modification of the fate of certain neurons along the midline.

In $g s b$ and ptc mutants, we see a complex pattern of cell fate alterations, as revealed by several probes. In many of the figures, the fu mutant CNS is shown as a typical example of a segment polarity mutant without clear CNS defects. The fu mutation was chosen for this illustration because the maternal effect allows us to produce a pure population of mutant embryos. Figure 1 schematically illustrates the neurons examined in our analysis of the CNS and the probes that detect these particular cells. It can be used as a reference guide for the data presented in subsequent figures. We illustrate a wild-type nervous system with its normal array of neurons and axons. Diagrams of the nervous systems of $p t c$ and $g s b$ mutants are included to highlight their pattem alterations.

\section{Pattern of anti-HRP antibody staining}

The first probe used to examine the pattern of the CNS system in the segment polarity mutants was the antiHRP antibody. The staining pattern clearly illustrates the segmentally repeated organization of the axons into connectives and commissures. In wild-type embryos (Fig. 2A), each segment has two commissures (anterior and posterior), and this is also the case in fu (Fig. 2D), arm, $c i^{D}$, and $\mathrm{Ce}$ mutants. In wg mutants (Fig. 2B), the commissures are not well formed but are present in some segments and are clearly present in younger mutant embryos. In hh mutants (Fig. 2C), the pattern of connectives and commissures is highly disorganized. A single large commissure per segment is formed by the fusion of the normal commissure pair in ptc mutants (Fig. 2E) (see also Pattern of fasciclin III expression, below). gsb mutants (Fig. 2F) also possess a single commissure per segment, but this is because the posterior commissure is almost nonexistent, whereas the anterior commissure seems fairly normal.

\section{Pattern of fasciclin III expression}

Fasciclin III expression is detected by staining with the 


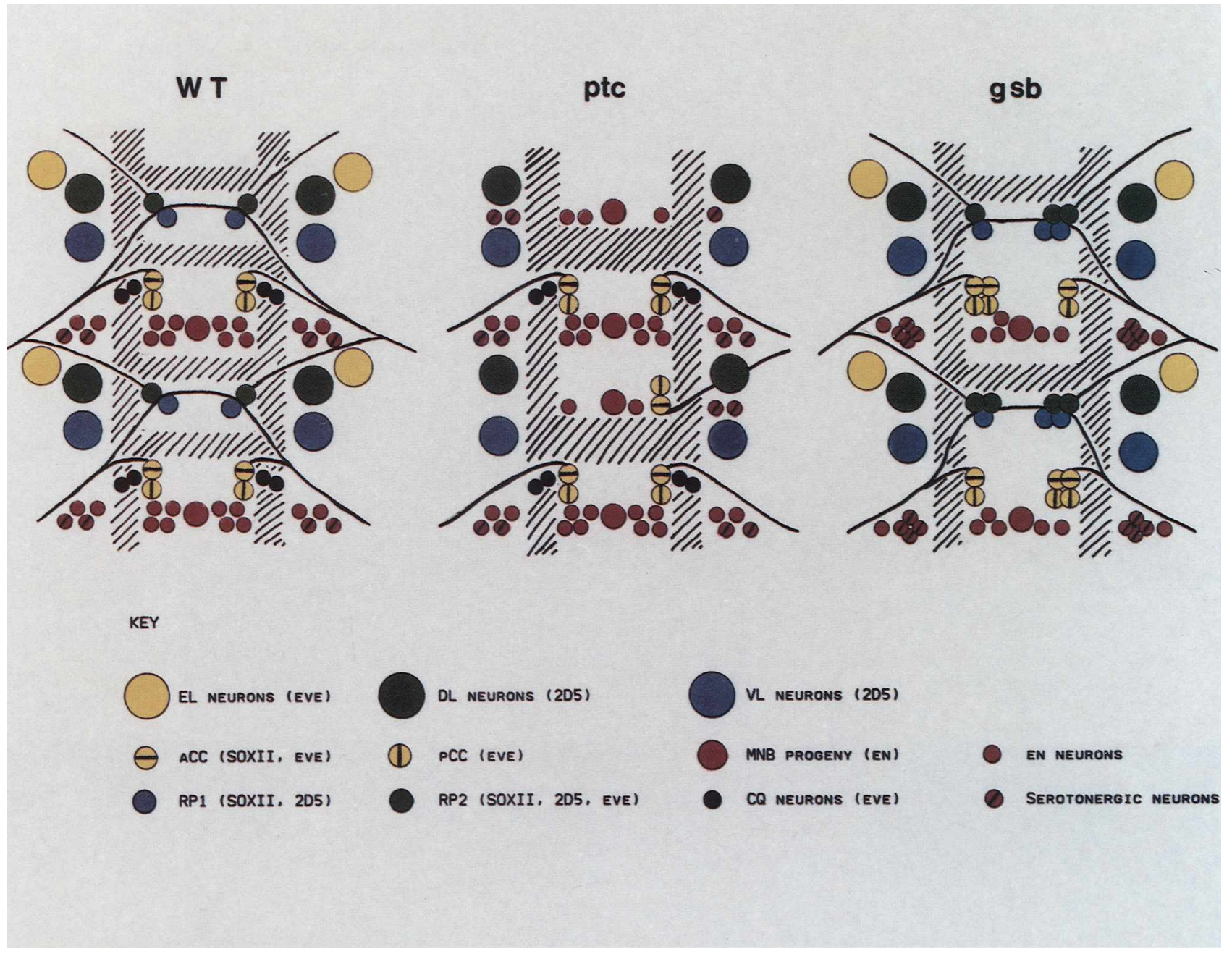

Figure 1. Summary diagram of diagnostic neurons and their alteration in $p t c$ and gsb mutants. Schematic illustration of several diagnostic neurons in wild-type, $p t c$, and gsb embryos. The key identifies specific neurons or neuronal clusters and the probes that recognize them. Diagrams illustrate pattems of deletions and duplications observed in ptc and gsb mutants (for details, see discussion).

$2 \mathrm{D} 5 \mathrm{mAb}$ (Patel et al. 1987). Within the CNS during germ-band extension, fasciclin III is expressed by the progeny of two to three NBs in the thoracic segments and the progeny of one to two NBs in the abdominal segments. One of the fasciclin III-positive lineages includes all the progeny of the NB that produces the neurons RPl, RP2, and RP3. A glial cell between the segmentally repeated neuronal lineages also expresses fasciclin III (Fig. 3A) (Patel et al. 1987). In $w g, h h$, $f u$, and gsb mutants, this early pattern appears normal (Fig. 3B-D,F). In ptc mutants (Fig. 3E), neuron expression is abolished in the abdominal segments and reduced to a single NB lineage in the thoracic segments. The glial cell expression, however, is normal. This indicates that the lineages of at least two NBs, including the NB producing the RP neurons, are deleted in ptc mutants.

In the 12-hr CNS, fasciclin III is expressed on a somewhat different set of neurons. Both the cell body and axons of RP1 and RP3 neurons (RP3 is located just ven- tral and medial to RP1) are clearly labeled by the 2D5 $\mathrm{mAb}$. Only the cell body of RP2 is labeled, and this labeling is weak and thus cannot be depended on for the identification of this cell. Two other cell bodies ventral to the RPI and RP3 cell bodies are also lightly labeled, but the rest of the cell bodies that previously stained during the germ-band-extended stage no longer express fasciclin III. Rather, two additional sets of cells are labeled at this stage, which were not part of the germband-extended expression pattern. The first set of approximately six cells (DL cells) is located dorsal, lateral, and just anterior to the RPs, and a second large set of cells (VL cells) sits ventral, lateral, and in the same anterior/posterior position as the RPs. Fasciclin III staining also reveals five axon bundles in the commissures: three in the anterior commissure and two in the posterior commissure (Fig. 4C). Many of the fasciclin III-positive axons that make up these bundles come from neurons that do not express fasciclin III on the surface of their 
Patel et al.
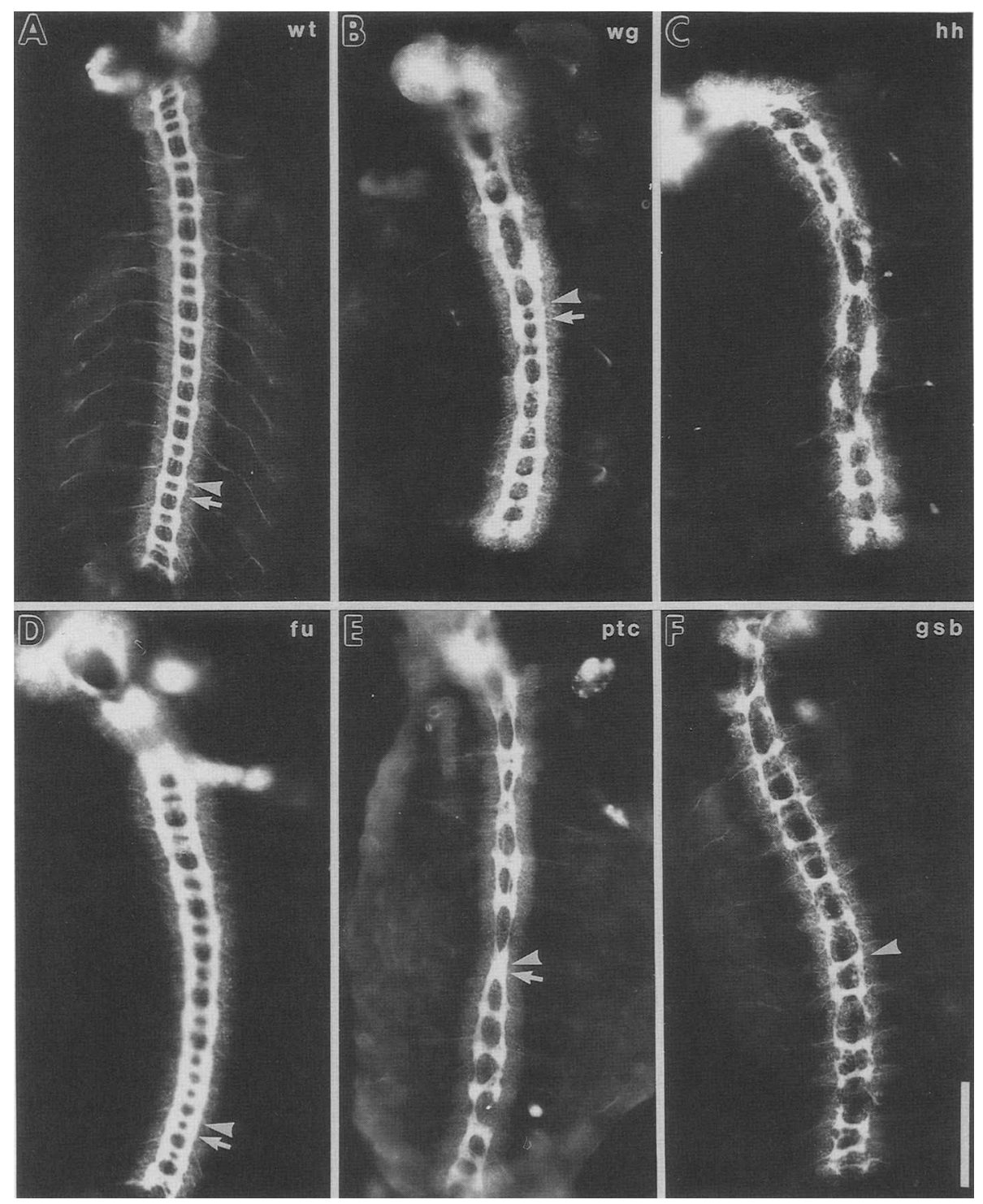

Figure 2. Anti-HRP antibody staining of the CNS in segment polarity mutants. Photographs of anti-HRP antibody staining in dissections of wild-type $(A), w g(B), h h(C), f u(D), p t c \mid E)$, and $g s b(F)$ embryos at $-12 \mathrm{hr}$ of development. Anterior is up, and view is onto the dorsal surface of the CNS. (A) Wild-type embryo shows the ladder-like arrangement of axons. There are a pair of commissures, anterior (arrowhead) and posterior (arrow), in every segment. $(B) \mathrm{wg}$ mutants reveal the commissure pairs in many segments. $|C| \mathrm{The}$ pattern in $h h$ mutants is highly disorganized. $(D)$ fu mutants possess a normal pattern. $\{E \mid$ A fusion of the two commissures forms one large commissure in ptc mutants; $|F|$ the single commissure per segment in gsb mutants is due to having normal anterior commissures and almost totally absent posterior commissures. Scale bar, $80 \mu \mathrm{m}$.

cell bodies. Thus, fasciclin III can be expressed regionally on the surface of a single neuron (Patel et al. 1987). The DL cells project their axons in bundle 1, and RP3 projects its axon in bundle 2. RP1 and about half of the VL cells project their axons in bundle 3 . The remaining VL axons traverse bundle 4 , and bundle 5 contains several axons, including one from a very weakly stained lateral cell body that cannot always be seen clearly.

The wild-type pattern of fasciclin III expression occurs in $f u, c i^{D}, C e$, and arm. In $w g$ mutants (Fig. 4E), there is some disorganization, but the basic pattern appears intact. However, a very strongly labeled cell next to RP1 is occasionally visible; in some embryos, this cell's axon appears to follow the RPI axon contralaterally and then posteriorly out the intersegmental nerve, whereas in other embryos it appears to project posteriorly out the intersegmental nerve on its own side. This neuron may represent a transformed RP2 neuron [see Fig. $4 \mathrm{E}_{\text {; }}$ and Pattern of $(e v e)$ expression, below]. hh mutants show a highly disorganized pattern at this time; many cells appear to be absent, and those that are present are hard to identify.

The fasciclin III expression pattern in ptc mutants (Fig. 4B,D) shows that the RP1, RP2, and RP3 neurons 


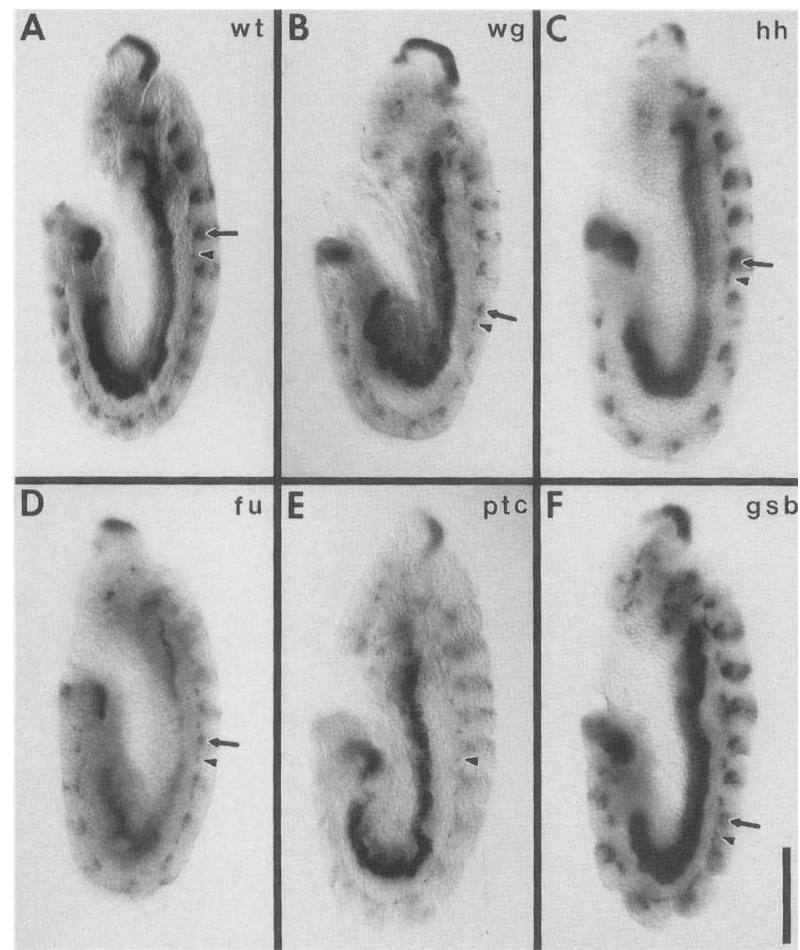

that normally sit between the commissures are absent, and this alteration may lead to the fusion of the commissures. The remaining fasciclin III-positive cell bodies (DL and VL) appear to be normal. The number of fasciclin III-labeled bundles in the commissures has been reduced to three, and careful analysis indicates that the two missing bundles ( 2 and 3 ) are those pioneered by
Figure 3. Fasciclin III expression in germ-band-extended embryos. Photographs of fasciclin III expression in whole-mount preparations of wild-type $(A), w g(B), h h(C), f u(D), p t c(E)$, and gsb $(F)$ embryos at $\sim 8 \mathrm{hr}$ of development as revealed by the 2D5 $\mathrm{mAb}$. Anterior is up and ventral is to the right. $(A)$ Wild-type embryo shows the expression in developing CNS by the progeny of several NBs, (arrow) and several glial cells (arrowhead). This same pattern is seen in wg $(B), h h(C), f u(D)$, and $g s b$ (F) mutants. (D) The neuron cluster in the fu embryo is smaller because the embryo shown is slightly younger than the others. (E) In the ptc mutant the glial cells are present (arrowhead marks glial cells in the third thoracic segment), but no neural progeny are present in the abdominal segments (posterior to ar rowheadl, and only a very few are present in the thoracic segments (anterior to arrowhead). The shadow-like bands through the nervous system of this embryo are not lightly stained neurons but there are because the 2D5-stained ectodermal stripes (Patel et al. 1987) extend abnormally far ventral in ptc mutants and create out-of-focus shadows. Scale bar, $90 \mu \mathrm{m}$.

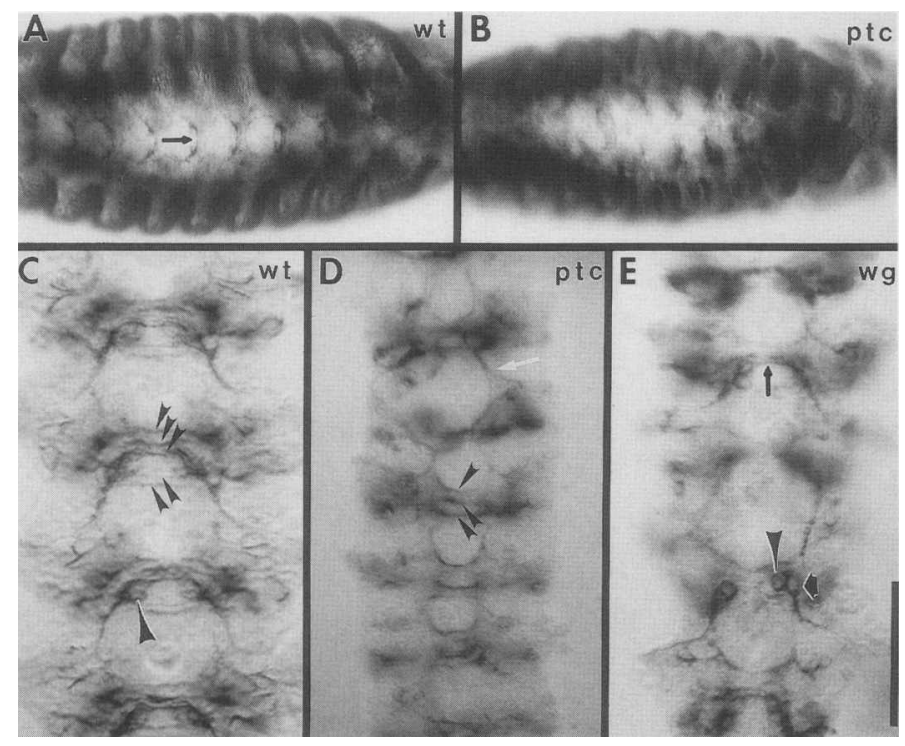

RP1 and RP3. With the elimination of bundle 3 , the VL cell bodies now project their axons into bundle 1, 4, or 5 , which results in the increased staining of these bundles, especially 4 and 5 . In addition, the axons of VL cells sometimes extend into the next most anterior segment and project across bundle 4 or 5 .

In $g s b$ mutants, the fasciclin III expression pattern is

Figure 4. Fasciclin III expression in germ-band-shortened embryos. Photographs of fasciclin III expression in wildtype $\{A, C\}, p t c \mid B, D\}$, and $w g|E|$ embryos at $\sim 10 \mathrm{hr}(A, B)$ and $12 \mathrm{hr}(C, D, E)$ of development, as revealed by the 2D5 $\mathrm{mAb}$. Anterior is to the right, and view is dorsal in $A$ and $B$. Anterior is up and view is dorsal in $C, D$, and $E .\{A\}$ Wild-type embryo shows the prominent RP1 cell body and axon (thin arrow) extending across the midline at this stage. (B) A ptc mutant of the same age shows no staining of an RPl cell body or axon. The complete absence of staining toward the midline at this stage indicates the absence of the RP1, RP2, and RP3 neurons. $(C)$ Wild-type embryo illustrates the five commissural bundles expressing fasciclin III, three in the anterior commissure (small arrowheads pointing downward) and two in the posterior commissure (small arrowheads pointing upward). The large arrowhead indicates an RP1 cell body. The VL and DL cells lie lateral to the commissures. $\langle D|$ Two of the 2D5-positive bundles in the anterior commissure are missing in the ptc mutant. Also, the white arrow points out an axon bundle from a set of VL neurons projecting into the next most anterior segment. (E) The wg mutant contains RP1 neurons (large arrowhead). The projection of the axon of this cell across the midline is out of focus in this segment but is visible in a more anterior segment (thin arrow) and seems to be normal. The wide arrow marks a neuron, which may be a transformed RP2, that is projecting posteriorly out of the ipsilateral intersegmental nerve (for details, see text). Scale bar, $120 \mu \mathrm{m}(A, B) ; 35 \mu \mathrm{m}(C) ; 90 \mu \mathrm{m}(D) ; 45 \mu \mathrm{m}(E)$. 
Patel et al.
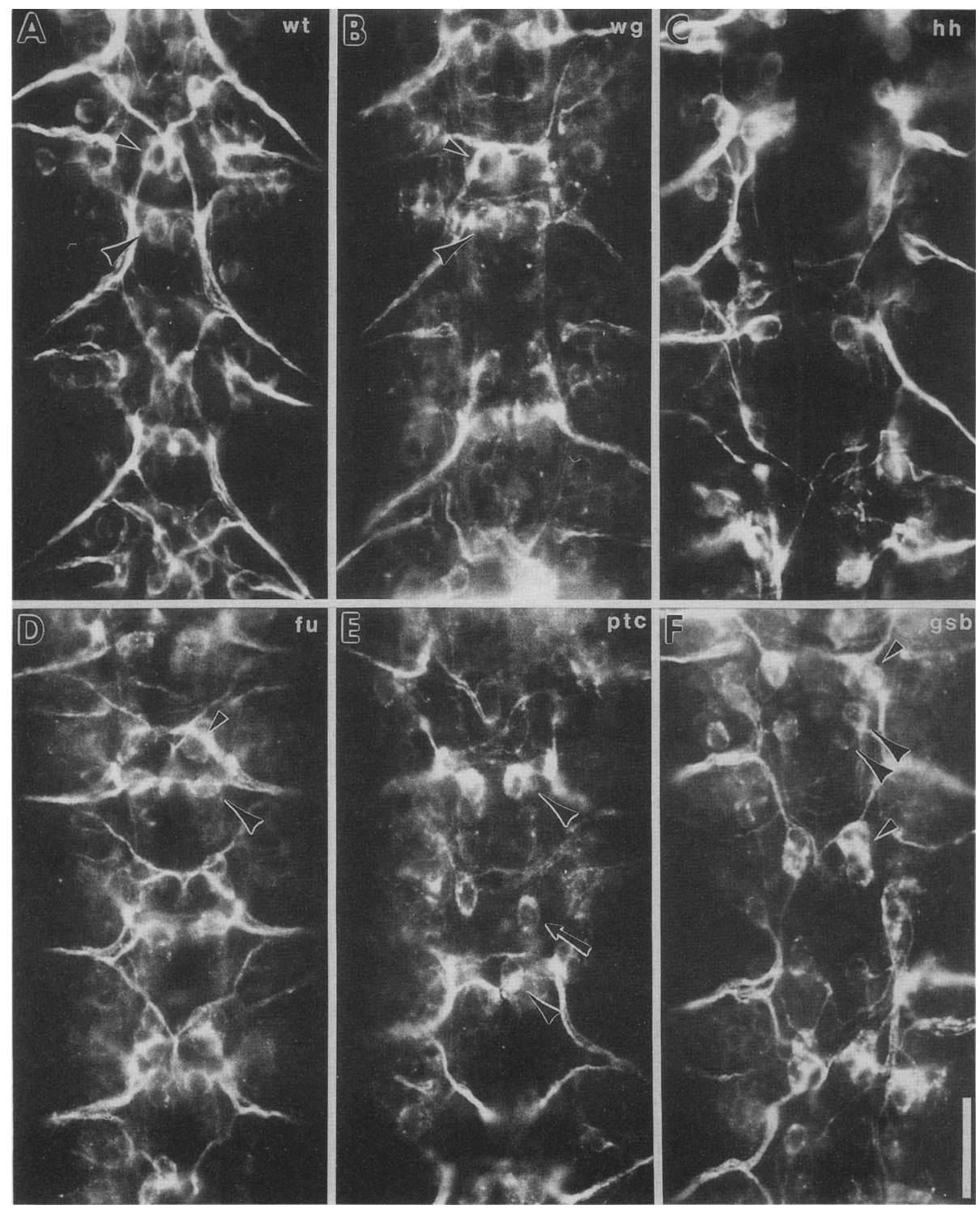

Figure 5. SOXII mAb staining of CNS. Photographs of SOXII expression in dissections of wild-type $(A), w g(B), h h(C), f u(D), p t c(E)$, and $g s b(F)$ embryos at about $12 \mathrm{hr}$ of development. Anterior is up, and view is dorsal. $(A)$ Wild-type pattern reveals the prominent aCC neuron (large arrowhead) and RPl neuron (small arrowhead). $(E)$ These neurons appear to be present in wg $(B)$ and $f u(D)$ mutants. $(C)$ The pattern is highly disorganized in $h h$ mutants. $|E|$ In ptc mutants, the large arrowheads point out normal aCCs in adjacent segments while the long arrow indicates a duplicated aCC sitting where an RP1 might be expected (for details, see text). $(F)$ In $g s b$ mutants the small arrowheads point towards clusters of RP neurons, and the pair of large arrowheads indicates a pair of aCCs (one normal plus one duplicate). Scale bar, $20 \mu \mathrm{m}$.

altered slightly. The position and number of the DL and VL neurons appear normal, but all of the VL axons tend to project in bundle 3 . Bundle 5 seems to form occasionally in what remains of the posterior commissure. The position of the RP neurons is normal, but the presence of the other fasciclin III-positive neurons in this region makes it difficult to see the duplication of the RPl and RP2 neurons, as is suggested by the SOXII and eve staining (see below).

\section{Pattern of SOXII mAb staining}

The SOXII mAb labels a subset of motor neurons in the
CNS starting at the initiation of axonogenesis. In each hemisegment, just posterior to the anterior commissure, SOXII labels the RP1 and the RP2 neurons, and just posterior to the posterior commissure it labels the aCC neuron. The known lineage (from NB 1-1) and the characteristic axon morphology of the aCC neuron make it particularly easy to identify. The SOXII staining is also seen in the cell bodies and axons of other motor neurons leading to the intersegmental nerve (Fig. 5A).

In wg mutants, the structure of the CNS is disrupted; labeled neurons are found in the correct positions for $\mathrm{RP} 1, \mathrm{RP} 2$, and aCC, but their organization is altered (Fig. $5 \mathrm{~B})$. In the $h h$ mutant, the pattern of neurons is drasti- 

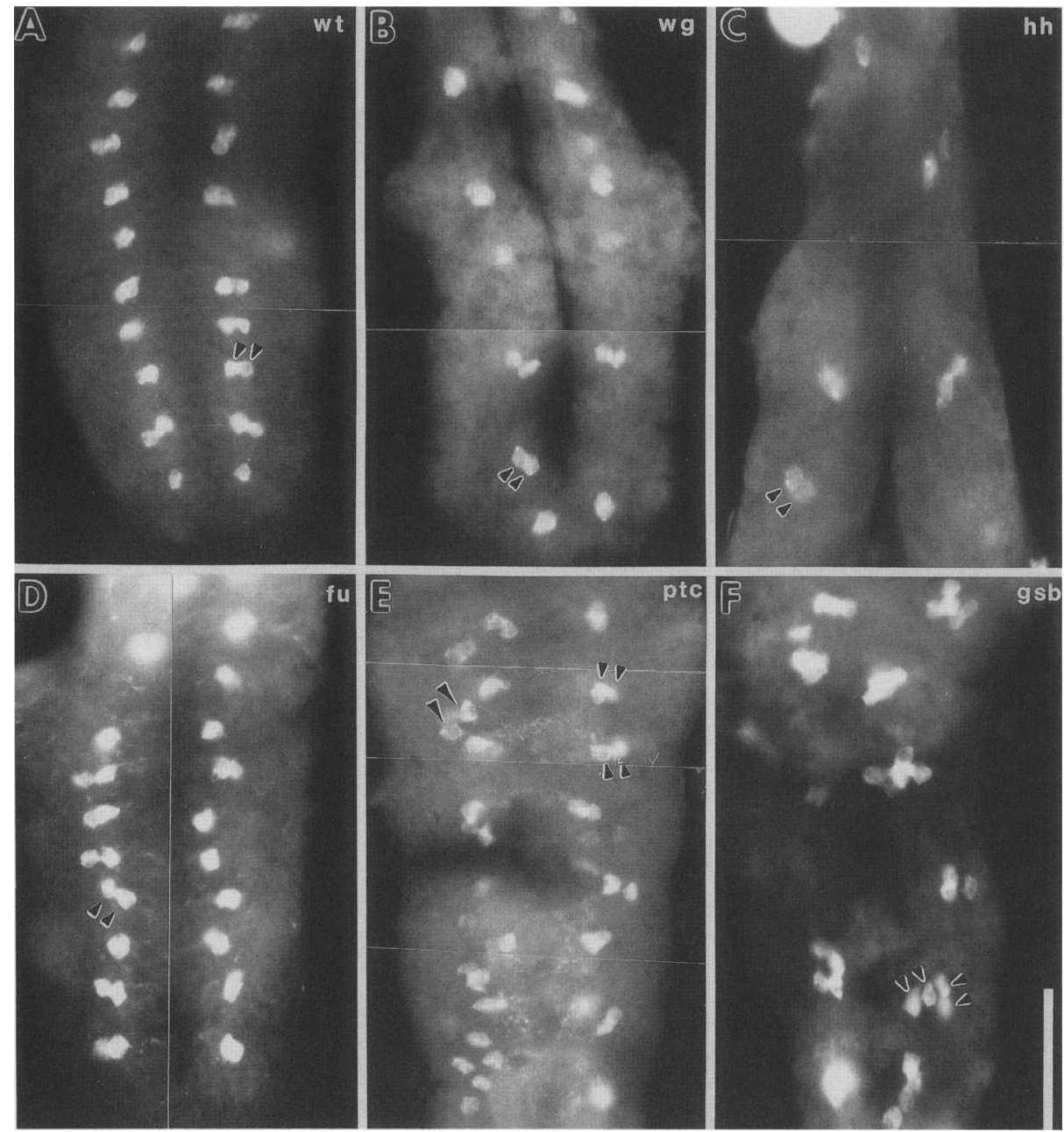

Figure 6. Serotonin expression in segment polarity mutants. Photographs of serotonergic neurons in dissections of wild-type $(A)$, wg $(B), h h|C|, f u(D), p t c|E|$, and $g s b(F)$ embryos at $\sim 20 \mathrm{hr}$ of development, as revealed by anti-serotonin antibody. Anterior is up, and view is dorsal. (A) Wild-type embryo contains a pair of serotonergic neurons per hemisegment (pair of arrowheads). One pair of serotonergic neurons is out of the plane of focus. These pairs are present in the normal pattern in fu $(D)$ embryos, usually present in wg $(B)$ embryo hemisegments, and only occasionally present within the hemisegments of $h h$ embryos $(C)$. (E) In the ptc mutant, the pairs of small arrowheads on the right point out pairs of serotonergic neurons in adjacent segments, and the large arrowheads on the left indicate a duplicated pair of serotonergic neurons positioned in between normal pairs. $(F)$ In gsb mutants, there are often four serotonergic neurons sitting together in a cluster (four small arrowheads). Scale bar, $45 \mu \mathrm{m}$.

cally disrupted, and it is difficult to identify specific neurons with confidence (Fig. $5 \mathrm{C}$ ). In the $\mathrm{fu}$, arm, $\mathrm{Ce}$, and $c i^{D}$ mutants, a relatively normal array of neurons and axons is present in most segments (Fig. 5D). The staining pattern of the SOXII monoclonal on ptc mutant nervous systems is quite different from that on wild type. Our interpretation of the pattern is that the RP1 and RP2 neurons are deleted and that the aCC neuron is occasionally duplicated (Fig. 5E). The duplicated aCC neuron lies in a position near to that of the original RPl and RP2 neurons, but we are confident that the labeled neurons are indeed aCC neurons. From the expression pattern of fasciclin III in ptc mutant nervous systems, we know that the RP neurons are deleted, and the alterations in the early fasciclin III expression pattern suggest that a block of NBs have been transformed in ptc mutants. In addition, the aCC neuron is among the earliest to label with SOXII and it can be recognized by the characteristic axonal process that it extends into the periphery. When early ptc mutant nervous systems are labeled with SOXII, segments occasionally contain a duplicated aCC that sends out a mirror-image symmetric process (data not shown). In gsb mutants, the SOXII pattern of labeling is also changed (Fig. 5F). The RP1, RP2, and aCC neurons are all present, but duplications appear to occur, at least in some segments. In Figure 5F, a large cluster of RP1 and RP2 neurons is located just posterior to the single segmental commissure, and a pair of aCC neurons can be seen in one segment.

\section{Pattem of serotonin expression}

The pattern of anti-serotonin antibody staining in the wild-type Drosophila CNS (Valles and White 1985) is 


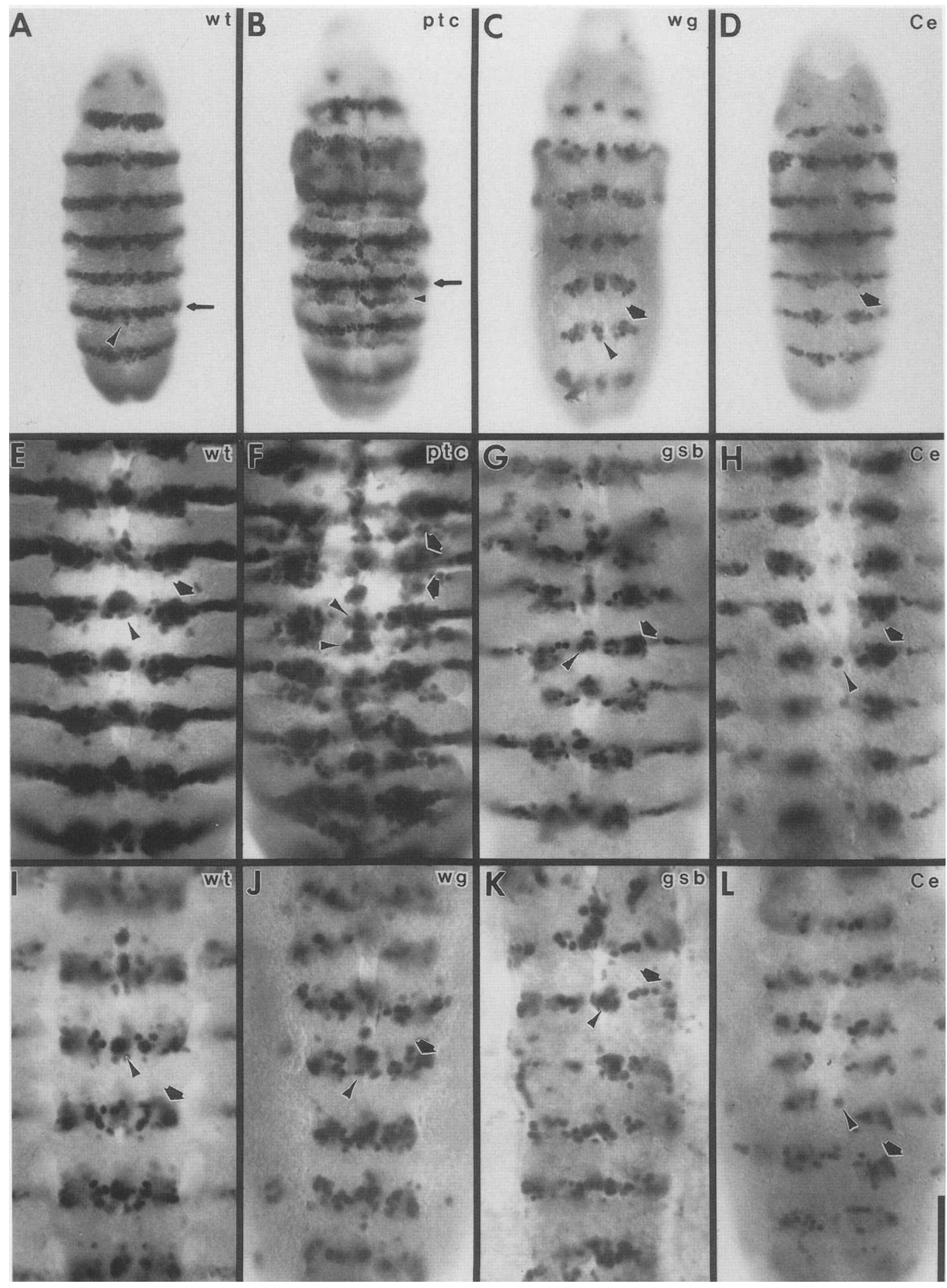

Figure 7. en expression expression in segment polarity mutants. Photographs of the expression of en in whole mounts of wild-type $\langle A, E, I)$, ptc $\{B, F \mid$, wg $\{C, I\}, g s b\{G, K\}$ and $C e\{D, H, L\}$ embryos at $8(A-D|, 10| E-H)$, and $12(I-L)$ hr of development, as revealed by anti-en $\mathrm{mAb}$. Anterior is up, and view is ventral. (A) Wild-type embryos show an en stripe over the en-positive neuroblasts (thin arrow) and the MNB and its progeny (arrowhead). (E,I) Later in development, the lateral neurons are more clearly visible (wide arrow) and the MNB progeny are slightly increased in number (arrowhead). In ptc mutants (B), there is an ectopic en stripe (small arrowhead; thin arrow is the normal stripel, an ectopic MNB progeny (horizontal arrowhead in $F$ ), and ectopic lateral neurons (wide horizontal arrow in $F$; slanted arrowheads and arrows indicate normal MNB progeny and lateral neurons in $F \mid(C)$ In wg mutants, the en stripes are missing, but the MNB and its progeny (arrowhead) and lateral neuroblasts (wide arrow) are present. Later in development $\langle J|$, the normal pattern of $M N B$ progeny (arrowhead) and lateral neurons (wide arrow) are present in wg mutants. $(G)$ gsb mutants at 10 hr possess fairly normal MNB progeny (arrowhead), lateral neurons (wide arrow), and en stripes. (K) By $12 \mathrm{hr}$ in development, expression in some of the lateral neurons (wide arrow) has decayed along with the en stripes. The MNB progeny expression, however, remains reasonably normal (arrowhead in $K$ ). In Ce mutants, the lateral neurons remain normal throughout development (wide arrows in $D, H, L$, but the MNB does not produce en-positive progeny (arrowhead in $H$ and $L$ points out the single MNB cell present). Scale bar, $90 \mu \mathrm{m}_{;}(A-D) 60 \mu \mathrm{m}_{i}(I-L) 40 \mu \mathrm{m}$. 


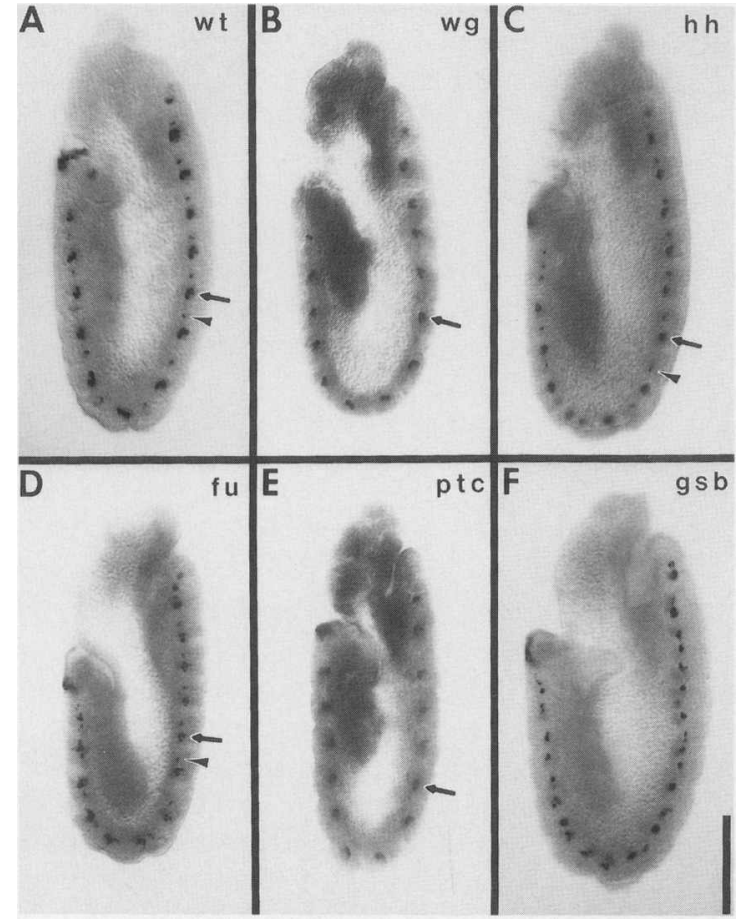

Figure 8. eve expression in germ-band-extended embryos. Photographs of anti-eve antibody staining in whole-mount wild-type $(A), w g(B), h h(C), f u(D), p t c(E)$, and $g s b(F)$ embryos at $\sim 7 \mathrm{hr}$ of development. Anterior is up and ventral is to the right. $|A|$ Wild-type embryo shows neuron cluster composed of $\mathrm{aCC}, \mathrm{pCC}$, and two CQs (arrow) and the offset RP2 neuron (arrowhead). This same pattern is present in $h h(C)$ and $C e(D)$ mutants. In both wg $(B)$ and ptc $(E)$ mutants, the cluster of neurons is present, but RP2 is absent. $(F)$ In the gsb mutant a string of eve-positive neurons is present all along the germ-band. Scale bar, $90 \mu \mathrm{m}$.

shown in Figure 6A. The last segment of the nervous system has a single serotonergic neuron per hemisegment, each abdominal and thoracic segment has a pair of serotonergic neurons per hemisegment, and the gnathal segments have clusters of three serotonergic neurons per hemisegment. In all segments, the serotonergic ncurons are located in the posterior part of each neuromere.

Figure 6 shows the abdominal and thoracic region, where we expect to see a pair of serotonergic neurons in each hemisegment in wild-type embryos. In wg mutants, the normal pair of serotonergic neurons is found in most hemisegments, but occasionally clusters are missing (Fig. 6B). In hh mutants, pairs of serotonergic neurons are found only sporadically along the nervous system (Fig. 6C). The pattern of serotonergic neurons in $\mathrm{fu}, \mathrm{arm}, \mathrm{Ci}^{\mathrm{D}}$, and $\mathrm{Ce}$ mutants is normal (Fig. 6D). In ptc mutants, additional clusters of paired serotonergic neurons are found in the middle of segments (Fig. 6E). In $g s b$ mutants, the paired serotonergic neurons are replaced by clusters of four serotonergic neurons (Fig. 6F).

\section{Pattern of en expression}

The anti-en $\mathrm{mAb}$ (N.H. Patel et al., in prep.) allows iden- tification of several neurons, including many that originate from the posterior part of the segment (Fig. 7A,E,I) (DiNardo et al. 1985; N.H. Patel and C.S. Goodman, in prep.). Expression of en in ectodermal stripes starts just after cellularization and is maintained throughout development (DiNardo et al. 1985). Most, but not all, of the neuronal staining underlies the ectodermal stripe of en expression. The most obvious elements to the pattern include several midline precursor (MP) progeny and the median neuroblast (MNB) and its progeny along the midline, and a large cluster of neurons located more laterally that are probably derived from approximately four NBs (per hemisegment), two in row 6 and two in row 7 (the last row).

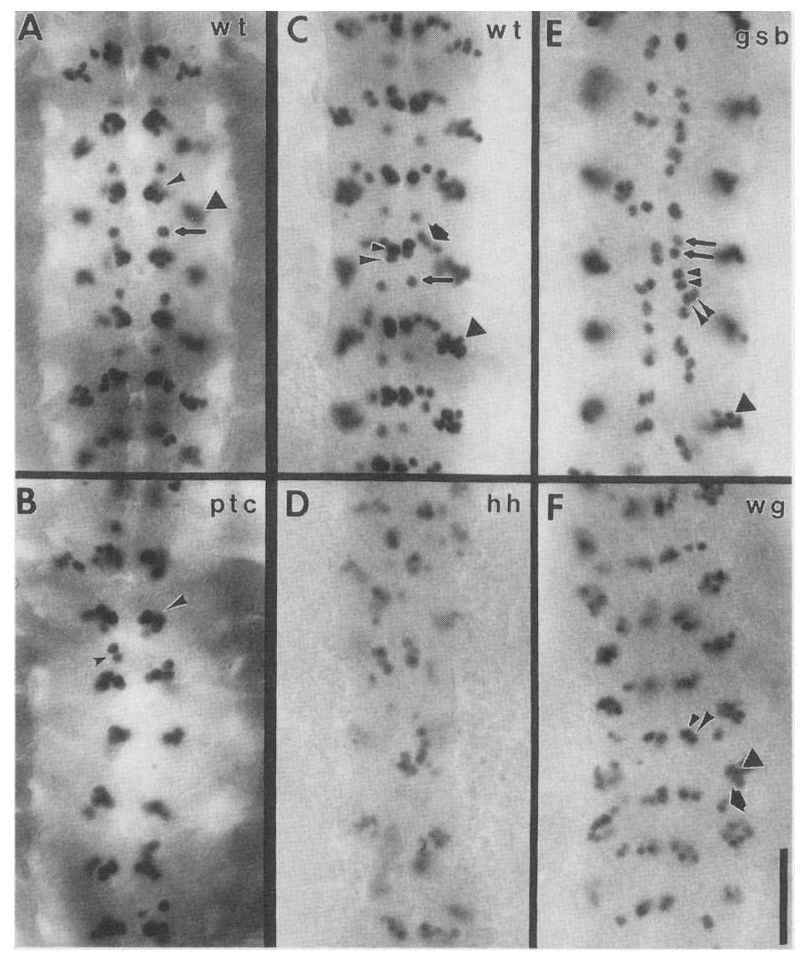

Figure 9. eve in germ-band-shortened embryos. Photographs of anti-eve antibody staining in whole-mount wild-type $(A, C)$, $p t c(B), h h(D), g s b(E)$, and $w g(F)$ embryos at $\sim 10 \mid A, B)$ and 12 $(C-F)$ hr of development. Anterior is up and view is ventral. At $10 \mathrm{hr}$, wild-type embryos show the aCC, pCC, CQ cluster (large arrowhead), RP2 (arrow), and lateral EL cluster (triangle). $(B \mid p t c$ mutants at the same stage are lacking the EL cluster and RP2 neuron but possess the aCC/pCC/CQ cluster (large arrowhead). Occasionally, a pair of neurons (small arrowhead) is seen where RP2 is expected and these are thought to be a duplicated aCC and pCC. $(C)$ The wild-type pattern at $12 \mathrm{hr}$ consists of an aCC (small arrowhead), a pCC (large arrowhead), the CQ neurons (wide arrow), RP2 neuron (thin arrow), and an EL cluster (triangle). $(D)$ The pattern in hh mutants is extremely disorganized. $|E|$ The gsb pattern includes the EL cluster but seems to be lacking the CQ neurons. In addition, there appears to be a pair of RP2s (thin arrows), aCCs (small arrowheads), and pCCs (large arrowheads) per hemisegment, although the duplications are not perfect in every segment. $(F)$ In the wg mutants, all the elements are present with the exception of the RP2 neuron. Scale bar, $40 \mu \mathrm{m}$. 
The pattern of en-positive neurons is normal in $w g$ (Fig. $7 \mathrm{C}, J$ ), even though wg mutants show a rapid deterioration of the ectodermal $e n$ stripes during the early part of the germ-band-extended period (DiNardo et al. 1988; Martinez-Arias et al. 1988). This indicates that en expression in the CNS is independent of wg and, therefore, is under different regulation. The en neuronal pattern appeared normal in germ-band-extended $h h$ embryos, but later in development $(\sim 10 \mathrm{hr})$ the pattern was highly disrupted and only a small number of scattered en-positive neurons were left by $\sim 12 \mathrm{hr}$ of development. $p t c$ mutants (Fig. 7B,F) show a partial duplication of en-positive neurons in the CNS in the region just anterior to the region of normal en expression. ptc mutants also show thin, ectopic en stripes in the ectoderm (DiNardo et al. 1988; Martinez-Arias et al. 1988), which are aligned with the ectopic CNS expression. This ectopic expression is visible at the time neuroblasts are beginning to form. Therefore, the expression of $e n$ is largely affected in the same way in both the CNS and the ectoderm in ptc mutants. In gsb mutants (Fig. $7 \mathrm{G}, \mathrm{K}$ ), the en stripe of neurons starts out normally and then decays after germband shortening to about one-half its normal width at the same time that the en ectodermal stripe is decaying in these mutants. It appears that the narrowing is due to the elimination of staining in the progeny of the row 6 neuroblasts. In $\mathrm{Ce}$ mutants (Fig. 7D, H, L), the lateral pattern elements appear normal, but a clear alteration is seen along the midline. There appear to be no en-positive MP progeny, and the single nucleus at the midline probably belongs to the MNB. In Ce mutants, this NB either does not produce any progeny or alternatively produces progeny that are not en positive. The ectodermal stripe in this mutant begins to decay during germ-band shortening. Normal patterns of en expression in the CNS were observed for fu and arm, with decay of the ectodermal stripe occurring during germ-band shortening. $c i^{D}$ mutants have not been examined for en expression.

\section{Pattern of eve expression}

Antibodies against eve allow the identification of $\sim 14$ neurons. Before germ-band shortening, each hemisegment contains a cluster of neurons composed of aCC, $\mathrm{pCC}$, and two $\mathrm{CQ}$ neurons (ventral to $\mathrm{aCC}$ and $\mathrm{pCC}$ ) and offset from this cluster lies the RP2 neuron (Fig. 8A). The pattern after germ-band retraction consists of these original neurons, plus three to four additional CQ neurons and a set of five to seven EL neurons that lie toward the lateral edge of the CNS posterior and ventral to $\mathrm{pCC}$ (Fig. 9A). As the CNS condenses, aCC, $\mathrm{pCC}$, and $\mathrm{RP} 2$ are progressively displaced toward the midline. One or two of the CQ neurons are also moved toward the midline, and the remaining CQ neurons stay near their original position (Fig. 9C).

wg mutants (Figs. $8 \mathrm{~B}$ and $9 \mathrm{~F}$ ) show a deletion of the RP2 neuron, with all other elements appearing normal. In ptc mutants, (Figs. $8 \mathrm{E}$ and $9 \mathrm{~B}$ ), the $\mathrm{CQ}$ neurons are normal and the EL neurons are deleted. The $\mathrm{aCC}$ and
pCC neurons are present, but the RP2 neuron is absent. The RP2 neuron is occasionally replaced by a pair of darkly staining eve-positive cells that may be duplications of aCC and pCC. In $g s b$ mutants (Figs. 8F and $9 \mathrm{E}$ ), the EL cells are present and the CQ cells are absent. In addition, the normal pattern of eve-stained aCC, pCC and RP2 cells is replaced by three pairs of eve-positive cells. These probably represent pairs of aCCs, pCCs, and RP2s. In hh mutants, the pattern is normal initially (Fig. $8 \mathrm{C})$ but then deteriorates after germ-band shortening (Fig. 9D). The pattern in arm, $c i^{D}$, and $C e$ mutants is normal (Fig. 8D). fu mutants have not been examined for eve expression.

\section{Discussion}

The segment polarity genes play a critical role in the formation of the Drosophila epidermis, where their function is required for the generation of proper pattern along the anteroposterior axis in each segment. Mutations in the segment polarity genes lead to the deletion of structures from each segment and, in certain cases to the mirror-image duplication of remaining structures (Nüsslein-Volhard and Wieschaus 1980). Because mutations in the segment polarity genes cause pattern defects in the same relative position within each segment, it has been proposed that these genes function to specify position and cell fate along the anteroposterior axis within each segment.

In this study we have examined the role of these genes during neurogenesis. We used a variety of antibodies to examine the pattern of individual neurons, particularly in the developing CNS, of eight segment polarity mutants to address the following questions. Which segment polarity genes are required for the proper development of the nervous system? What is the nature of the nervous system defect in segment polarity mutants? Is the pattern of defects in the nervous system homologous to that seen in the epidermis? Do any of the mutant phenotypes suggest a role for these genes during neurogenesis that is distinct from their regional specification of the epidermis?

\section{Segment polarity mutants have homologous pattern defects in the epidermis and the PNS}

In the PNS, pattern defects occur in all the segment polarity mutants, and these alterations appear to be homologous to the defects observed in the epidermis. This suggests that the same mechanism is used to specify positionally the cells in the epidermis and the neurons in the PNS. This result is not surprising, because the cells that give rise to the PNS are located within the epidermis and do not leave the epidermal layer until germ-band shortening (Campos-Ortega and Hartenstein 1985). It is known that the $g s b$, ptc, and $w g$ genes are active during germ-band extension (Nüsslein-Volhard and Wieschaus 1980; Bopp et al. 1986; Baker 1987; Baumgartner et al. 1987; Cote et al. 1987; Martinez-Arias et al. 1988). Therefore, during the time of segment polarity gene 
function, the progenitor cells of the PNS are still part of the epidermal layer and presumably are able to respond to the the same positional information that specifies the epidermis.

\section{Three segment polarity mutants have a relatively normal CNS}

Of the eight segment polarity mutants examined, only five-wg, $h h, C e, p t c$, and $g s b$-showed alterations in the pattern of neurons within the CNS. In fu, arm, and $c i^{D}$ mutants, the nervous system was not perfect, but the normal set of diagnostic neurons were typically present. Our negative results carry the caveat that we were only assaying a small number of neurons and that the mutant phenotypes may not have been amorphic. Nevertheless, it appears likely that the $f u$, arm, and $c i^{D}$ genes act primarily in the epidermis, and are probably performing functions specific to the epidermis at a time after the NBs have delaminated.

The hh mutant has a global and possibly late defect in the CNS

Mutations in the $h h$ gene cause extreme alterations in the pattern of the CNS. The anti-HRP antibody staining pattern shows disorganization in the pattern of axon pathways. The $2 \mathrm{D} 5 \mathrm{mAb}$ (anti-fasciclin III) occasionally stains neurons that may be RPl, the SOXII mAb stains an array of neurons that bears no resemblance to its normal pattern, and serotonergic neurons are present but only in a few segments. The variability in the pattern between segments and the severe nature of the defects, make the interpretation of the mutant phenotype very difficult. The fact that the fasciclin III and eve patterns appear normal during germ-band extension but then deteriorate rapidly shortly thereafter suggests that the initial patterning may be normal but the CNS may become disorganized because of secondary causes. Given the appearance of the CNS, it is possible that widespread cell death is responsible for this transition.

The wg, Ce, ptc, and gsb mutants have specific defects in the CNS

The defect in wy mutants is quite subtle. The anti-eve antibody labels all of its normal neurons, with the exception of RP2, which does not stain in wg mutants. However, RP2's sibling, RP1, is present. In addition, the fasciclin III staining pattern of this entire lineage during the germ-band-extended period indicates that the other neurons of this lineage, such as RP3, are present. Previous experiments (Doe et al. 1988a) indicated that lack of eve expression in RP2 transforms it toward the fate of its sibling, RP1. Thus, it is possible that there are two RP1 neurons in each hemisegment and no RP2 neuron in $w g$ mutants. This would explain the additional fasciclin III-positive neuron next to RP1. This alteration may have been missed with the SOXII antibody, as both RP1 and RP2 are SOXII-positive, and both normally follow pathways filled with SOXII-labeled axons. The lack of some serotonergic cells and fusion of commissures may be due to a general deterioration of the CNS that occurs late in development.

In summary, the results indicate that the $w g$ CNS defect is far less extensive than the ectodermal defect. The results suggest further that $w g$ and en interact differently in the CNS than in the epidermis. For example, the posterior en-positive neurons are normal in the CNS of wg mutants, whereas the ectoderm in such mutants shows deletion of the posterior regions of cuticle. Moreover, in wg mutants, en expression in the ectoderm is eliminated shortly after germ-band extension, whereas en expression in the CNS is not. This indicates that unlike in the epidermis, wg does not control the expression of $e n$ in the CNS.

$w g$ is thought to be involved in cell-cell communication in the ectoderm because: (1) it appears to act in a non-cell autonomous fashion (Morata and Lawrence 1977); (2) the region of deleted cuticle exceeds the region of wg expression (Baker 1987); and (3) the sequence data suggest that the protein product is secreted (Rijsewijk et al. 1987). In this context, it is interesting to note that the choice of cell fate between sibling neurons involves local interactions between these cells (Kuwada and Goodman 1985). The only effect of $w g$ mutants that we have observed in the developing CNS is on the determination of a single neuron, RP2, which is one of a pair of neurons that must interact to specify their fates. Thus, $w g$ may play a role in allowing the communication between the sibling neurons RPI and RP2. Without this normal interaction, both cells fail to express eve and may thus be acquiring identical fates. We are attempting to observe whether any other sibling pairs show similar transformations in $\mathrm{wg}$ mutants.

$\mathrm{Ce}$ mutants show a lack of en-positive MP progeny and a MNB which, if present, fails to produce progeny or alternatively generates progeny that do not express en. It is possible that the defects in Ce mutants reflect an indirect influence from the epidermis on these neurons. It is also possible that $\mathrm{Ce}$ may play some specific role in specifying the fates of certain midline neurons, or the phenotype may reveal a role for this gene in controlling certain neuronal division patterns.

In $p t c$ and $g s b$ mutants, we find numerous alterations in the pattern of neurons. Summary diagrams indicating the positions of the labeled neurons in the CNS of wildtype, $p t c$, and gsb embryos are shown in Figure 1.

The CNS phenotype of ptc mutants resembles its ectodermal defects in several ways. The region of deletion in the epidermis is around the middle of the segment; the deleted cells in the CNS, the RP neurons, and the EL cells are located in the middle of the nervous system segment. Because a number of the deleted cells normally sit between the two commissures and appear to be involved in keeping these axon pathways separated ( $R$. Jacobs, pers. comm.), this pattern alteration may be responsible for the formation of the fused commissures. It is important to note, however, that not all neurons in 
the middle of the CNS segments are affected. For example, the VL cells lie in the same anterior-posterior position as the RP neurons but they are not deleted (see Fig. 4D|. The additional fasciclin III-positive neuroblast of the thoracic segments probably sits anterior to the pattern deletion of $p t c$, and thus its progeny are still present.

Therefore, it appears as though ptc controls the fate of only a subset of neurons underlying the region of ectoderm that it controls. From this, we predict that ptc would be expressed in a solid stripe in the ectoderm, but expression would be heterogeneous in the nervous system, reflecting the pattern of neurons that do and do not require $p t c$ function.

In ptc mutants, the replacement of deleted cells by duplicated cells from the ends of the segment may be occurring. The serotonergic cells are clearly duplicated in the middle of the segment; these cells are known to originate from an NB in the last NB row of each segment. The en stripe is partially duplicated in the ectoderm of ptc mutants; in a similar fashion, the en-positive neuroblasts and neurons, which define the posterior region of each CNS segment, appear to undergo a duplication. Consequently, duplicated en-positive neurons come to lie toward the middle of the segment. The aCC and $\mathrm{pCC}$ neurons are also occasionally duplicated; these cells are from NB 1-1 in the first row of each segment (though these are two of the very few cells that migrate to their final position). The ptc gene probably controls neuronal determination at the level of the NBs because we see deletions of entire NB lineages and duplications of entire lineages (see Figs. 3E and $7 F$ ).

The defects seen in gsb mutants are more complex. There are deletions that seem to involve cells that reside in the more posterior regions of each CNS segment. For example, en expression after germ-band shortening is narrowed to a thinner stripe of cells. Within a wild-type hemisegment, en is expressed by progeny from two neuroblasts in the NB row 6 and two in the NB row 7 (N.H. Patel et al., in prep.). It is possible that the progeny of the NB row 6 lose en expression and those of NB row 7 are unaffected. The CQ cells are also deleted, and the lack of a posterior commissure may reflect the absence of certain landmark neuronal or nonneuronal cells from this region. The pattern of duplications is not as clear as in $p t c$. The serotonergic neurons sit near the edge of the deletion (based on the en data), and they appear to be duplicated (see Fig. 6F). These pattern alterations might be tied in with the changes that occur in the ectoderm.

In addition, an interesting set of duplications occurs in $g s b$ mutants in the region of the $\mathrm{ACC}, \mathrm{pCC}$ and RP1, RP2 neurons. The anti-eve staining suggests that certain individual cells are replaced by pairs of cells. The SOXII data also indicate that there are extra pairs of SOXII-positive cells in the area. The duplicated cells do not seem to be made in only the regions of the deletions /see Figs. $8 \mathrm{~F}$ and $9 \mathrm{E}$ ) but occur all along the length of each neuromere. One possibility for this pattern of duplications is that the $g s b$ gene may be required for the normal cell lineage process to occur, i.e., for NBs to generate their proper lineage of GMCs. For example, the gsb product might be responsible for making the first GMC of a NB different from the second GMC of that same NB. In the absence of $g s b$ product, the second GMC might become equivalent to the first. This would lead to the tightly coupled pairs of duplicated neurons that are seen throughout the CNS.

Indeed, the RP1 and RP2 neurons, the $\mathrm{aCC}$ and $\mathrm{pCC}$ neurons, and the pair of serotonergic neurons are all thought to be siblings that arise from the first GMC from three different neuroblasts (Taghert and Goodman 1984; Kuwada and Goodman 1985; Patel et al. 1987). As of yet, we have no idea how the fates of subsequent GMCs in these lineages are affected. A series of primary neuronal culture experiments that are in progress might help test our hypothesis and allow a better analysis of the lineage modifications in $g s b$ mutants.

One final caveat to the analysis we have presented with all of our probes has to do with our ability to identify duplicated cell types properly. In a wild-type embryo, cells are most often identified on the basis of their position and axon morphology, but when these cells are born in new positions, these criteria cannot be used alone. We then try to identify cells based on their expression of specific molecules, but this can lead to complex problems. The genes involved in neuronal determination may work in a combinatorial manner just as segmentation genes do earlier in development. It is possible that the elimination of one of these components can create a cell containing a combination of determinants that does not normally exist in any cell of a wild-type embryo. This could lead to abnormal development in which a single neuron might express products normally restricted to different lineages. Fortunately, many of the changes we see are paralleled by various markers, suggesting that our basic observations are sound.

In conclusion, several segment polarity mutations do not cause noticeable alterations in neuronal cell determination within the CNS. One gene, $h h$, causes a severe defect that may simply be due to secondary causes.

The segment polarity mutation ptc causes a set of duplications and deletions that reflect its cuticle phenotype in certain respects. We believe that this gene may be involved in the process of positionally specifying a subset of NBs. A second mutation, gsb, gives rise to deletions that correspond to the deletions in the cuticle, but the pattern of duplications suggest a more complex role. One hypothesis is that in addition to this gene's role in positional specification, it may also play a role in GMC determination within specific NB lineages. The $C e$ gene may be important for providing positional information to certain neural precursors along the midline and/or may play a role in controlling the division patterns of these same midline cells. wg mutants appear to have a very subtle defect that does not correspond to their cuticular defect: A single neuron, RP2, is missing, whereas other neurons in its lineage appear normal. This nervous system defect could imply that the wg gene serves a role in the cell-cell communication that allows sibling neurons to interact and take on different fates. 


\section{Methods}

Drosophila stocks

The $c i^{D} / M^{63 a}$ and the $w g^{I G 22} \mathrm{cn} b w s p / C y O$ stocks were obtained from the Bowling Green Stock Center. C. Nüsslein-Volhard provided the $c n b w$ sp DfIIX62/CyO, b pr BI cn DfSB1/ SM1 (deficiencies of the gsb locus), and $c n$ ptc ${ }^{I N 108} b w s p / C y O$ stocks. The $h h^{13 C 26}$ st $e / T M 3 S b$ and the $y$ arm ${ }^{X K 22 / F M 7 ~ s t o c k s ~}$ were obtained from E. Wieschaus. N. Baker and B. Hochman provided the $\mathrm{wg}^{\mathrm{CX} 4} \mathrm{~b}$ pr/CyO (a transcript null) and $\mathrm{Ce}^{2 / e y^{D}}$ stocks, respectively. The $f_{u^{94}}$ mutation was an X-ray-induced allele with very good expressivity of the fu segmentation defect.

\section{Immunofluorescence}

Whole mounts Embryos were dechorionated in a 1:1 mixture of Clorox and water and fixed for $20 \mathrm{~min}$ at the interface between heptane and $4 \%$ paraformaldehyde in $1 \times$ PBS. The vitelline membranes were removed by replacing the fix with an equal volume of methanol and shaking the tube vigorously. The heptanc and methanol solutions were removed, and the embryos were washed twice in methanol (Mitchison and Sedat 1983!. The embryos were then washed three times for $10 \mathrm{~min}$ each in BSS $155 \mathrm{~mm} \mathrm{NaCl}, 40 \mathrm{mM} \mathrm{KCl}, 15 \mathrm{~mm} \mathrm{MgSO}, 5 \mathrm{~mm}$ $\mathrm{CaCl}_{2}, 10 \mathrm{mM}$ Tricine-buffer, $20 \mathrm{~mm}$ glucose, $50 \mathrm{~mm}$ sucrose, 1 $\mathrm{mg} / \mathrm{ml}$ bovine serum albumin (fraction $\mathrm{V})(\mathrm{pH} 7.0)$ ]. (Chan and Gehring 1971), followed by one 30-min wash in TFN [150 mM $\mathrm{NaCl}, 50 \mathrm{~mm}$ Tris- $\mathrm{HCl}(\mathrm{pH} 7.4), 5 \%$ fetal bovine serum, $0.5 \%$ NP-40].

Dissections Embryos 10-12 hr old were dechorionated in a $1: 1$ mixture of Clorox and water and transferred to a piece of double-stick tape. The embryos were covered with BSS and removed from the vitelline membranes by making a hole in the membrane near the head region of the embryos with a glass needle and carefully teasing the embryos out. The embryos were transferred to a ring chamber containing BSS that was mounted on a poly-L-lysine-coated coverslip. The embryos were oriented dorsal side up and dissected with glass needles by peeling back the epidermis and removing the gut and yolk sac to expose the nervous system. Dissected embryos were fixed for $20 \mathrm{~min}$ by adding an equal volume of $4 \%$ paraformaldehyde fix to the chamber. The fix and BSS solutions were removed and the embryos were washed once in TBS $[150 \mathrm{~mm} \mathrm{NaCl}, 50 \mathrm{~mm}$ Tris- $\mathrm{HCl}\langle\mathrm{pH} 7.4\rangle \mid$, followed by one $30 \mathrm{~min}$ wash in TFN.

Embryos 20-24 hr old were collected and removed from their vitelline membranes as described above. The CNS was separated in BSS from the rest of the embryo with tungsten needles and processed like the previous dissections.

Antibody staining Embryos were stained by replacing the TFN with an equal volume of the desired antibody diluted with TFN. Primary antibody dilutions: SOXII $(1: 3)$, anti-serotonin (Immuno Nuclear) $(1: 1000)$. The embryos were incubated overnight at $4^{\circ} \mathrm{C}$. After four 30 -min washes in TFN, a Texas red-linked secondary antibody (Amersham) was diluted $1: 50$ with TFN and incubated with the embryos for $6 \mathrm{hr}$ at $4^{\circ} \mathrm{C}$. After four 20-min washes in TFN, the whole-mount and dissected embryos were double-labeled with fluorescein-conjugated antiHRP antibody (Cooper Biomedical), diluted $1: 200$ with TFN. The embryos were incubated for $1 \mathrm{hr}$ at room temperature and washed three times, for $15 \mathrm{~min}$ each in TFN. The embryos were mounted in a solution of $80 \%$ glycerol, $4 \% n$-propyl galate, 20 mM Tris- $\mathrm{HCl}(\mathrm{pH} 7.5)$.

\section{HRP immunocytochemistry}

All 2D5, en, and eve antibody staining on whole-mount em- bryos was done following the procedure described previously in Patel et al. (1987), with the following modifications: Embryos were fixed for $45 \mathrm{~min}$ (instead of $10 \mathrm{~min}$ ), and the biotin/ avidin-HRP system was replaced by HRP-conjugated goat anti-mouse or rabbit antibodies (Jackson Immunoresearch Labs) used at a concentration of $1: 200$. The $2 \mathrm{D} 5$ and anti-en mAbs were used at a $1: 1$ dilution, and the affinity-purified rabbit anti-eve antibody was used at a concentration of $1: 50$.

\section{Acknowledgments}

We thank April Ewton and Gary Ghiselli for their technical assistance, Manfred Frasch and Mike Levine for the anti-eve antibody, and Kevin Coleman and Tom Kornberg for the anti-en mAb. We also thank Nick Baker, Yash Hiromi, Alex Kolodkin, Chris Doe, Steve DiNardo, Roger Jacobs, and Iva Greenwald for their many helpful discussions, comments, and suggestions. This work was supported by the National Institutes of Health (grant R01 NS18366) and the Howard Hughes Medical Institute (to C.S.G.) and by Basil $\mathrm{O}^{\prime}$ Connor Starter Scholar Research Award No. 5-572 from the March of Dimes Birth Defects Foudation and National Science Foundation DCB85-13504 (to R.H.).

\section{References}

Akam, M. 1987. The molecular basis for metameric pattern in the Drosophila embryo. Development 101: 1-22.

Artavanis-Tsakonas, S. 1988. The molecular biology of the Notch locus and the fine tuning of differentiation in Drosophila. Trends Genet. 4: 95-100.

Baker, N. 1987. Molecular cloning of sequences from wingless, a segment polarity gene in Drosophila: The spatial distribu tion of a transcript in embryos. EMBO /. 6: 1765-1773.

1988. Embryonic and imaginal requirements of wingless, a segment-polarity gene in Drosophila. Dev. Biol. 125: 96-108.

Bate, C.M. 1976. Embryogenesis of an insect nervous system. I. A map of the thoracic and abdominal neuroblasts in Locusta migratoria. J. Embryol. Exp. Morph. 35: 107-123.

Baumgartner, S., D. Bopp, M. Burri, and M. Noll. 1987. Structure of two genes at the gooseberry locus related to the paired gene and their spatial expression during Drosophila embryogenesis. Genes Dev. 1: 1247-1267.

Bopp, D., M. Burri, S. Baumgartner, G. Frigerio, and M. Noll. 1986. Conservation of a large protein domain in the segmentation gene paired and in functionally related genes of Drosophila. Cell 47: 1033-1040.

Campos-Ortega, J.A. 1988. Cellular interactions during early neurogenesis of Drosophila melanogaster. Trends Neurosci. 11: 400-405.

Campos-Ortega, J.A. and V. Hartenstein. 1985. The embryonic development of Drosophila melanogaster. Springer-Verlag, Berlin.

Carroll, S.D. and M.P. Scott. 1985. Localization of fushi tarazu protein during Drosophila embryogenesis. Cell 43: 47-57.

Chan, L.-N. and W. Gehring. 1971. Determination of blastoderm cells in Drosophila melanogaster. Proc. Natl. Acad. Sci. 68: 2217-2221.

Cote, S., A. Preiss, J. Haller, R. Schuh, A. Kielin, E. Seifert, and H. Jackle. 1987. The gooseberry-zipper region of Drosophila: Five genes encode different spatially restricted transcripts in the embryo. EMBO /. 6: 2793-2802.

DiNardo, S., J.M. Kuner, I. Theis, and P.H. O'Farrell. 1985. De- 
velopment of embryonic pattern as revealed by accumulation of the nuclear engrailed protein. Cell 43: 59-69.

DiNardo, S., E. Sher, J. Heemskerk-Jongens, J.A. Kassis, and P.H. O'Farrell. 1988. Two-tiered regulation of spatially patterned engrailed gene expression during Drosophila cmbryogenesis. Nature 332: 604-609.

Doe, C.Q. and C.S. Goodman. 1985a. Early events in insect neurogenesis: I. Development and segmental differences in the pattern of neuronal precursor cells. Dev. Biol. 111: 193205.

- 1985b. Early events in insect neurogenesis: II. The role of cell interactions and cell lineage in the determination of neuronal precursor cells. Dev. Biol. 111: 206-219.

Doe, C.Q., D. Smouse, and C.S. Goodman. 1988a. Control of neuronal fate by the Drosophila segmentation gene evenskipped. Nature 333: 376-378.

Doe, C.Q., Y. Hiromi, W.J. Gehring, and C.S. Goodman. 1988b. Expression and function of the segmentation gene fushi tarazu during Drosophila neurogenesis. Science 239: 170175

Fjose, A., W.J. McGinnis, and W.J. Gehring. 1985. Isolation of a homeo box-containing gene from the engrailed region of Drosophila and the spatial distribution of its transcripts. Nature 313: 284-289.

Frasch, M., T. Hoey, C. Rushlow, H. Doyle, and M. Levine. 1987. Characterization and localization of the even-skipped protein of Drosophila. EMBO I. 6: 749-759.

Goodman, C.S., M.J. Bastiani, C.Q. Doe, S. du Lac, S.L. Helfand, I.Y. Kuwada, and I.B.Thomas. 1984. Cell recognition during neuronal development. Science 225: 1271-1279.

Hartenstein, V. and J.A. Campos-Ortega. 1984. Early neurogenesis in wild-type Drosophila melanogaster. Wilhelm Roux's Arch Dev. Biol. 193: 308-325.

Hiromi, Y., A. Kuroiwa, and W.J. Gehring. 1985. Control elements of the Drosophila segmentation gene fushi tarazu. Cell 43: 603-613.

Ingham, P. 1988. The molecular genetics of embryonic pattern formation in Drosophila. Nature 335: 25-34.

Jan, L.Y. and Y.N. Jan. 1982. Antibodies to horseradish peroxidase as specific neuronal markers in Drosophila and in grasshopper embryos. Proc. Natl. Acad. Sci. 79: 2700-2704.

Jürgens, G., E. Wieschaus, C. Nüsslein-Volhard, and $H$ Kluding, 1984. Mutations affecting the pattern of the larval cuticle in Drosophila melanogaster. II. zygotic loci on the third chromosome. Wilhelm Roux's Arch. Dev. Biol. 193: $283-295$

Kornberg, T., I. Siden, P. O'Farrell, and M. Simon. 1985. The engrailed locus of Drosophila: In situ localization of transcripts reveals compartment-specific expression. Cell 40: $45-53$

Kuwada, J.Y. and C.S. Goodman. 1985. Neuronal determination during embryonic development of the grasshopper nervous system. Dev. Biol. 110: 114-126.

Lindsley, D.L. and E.H. Grell. 1967. Genetic variations of Drosophila melanogaster. Carnegie Institution of Washington, Washington.

Macdonald, P.M., P. Ingham, and G. Struhl. 1986. Isolation, structure, and expression of even-skipped: A second pairrule gene of Drosophila containing a homeo box. Cell 47: $721-734$

Martinez-Arias, A., N. Baker, and P. Ingham. 1988. The role of segment polarity genes in the definition and maintenence of cell states in the Drosophila embryo. Development 103: $157-170$.

Mitchison, T.J. and J. Sedat. 1983. Localization of antigenic determinants in whole Drosophila embryos. Dev. Biol. 99: $261-264$.
Morata G, and P.A. Lawrence. 1977. The development of wing Iess, a homeotic mutation of Drosophila. Dev. Biol. 56: 227-240.

Nüsslein-Volhard, C. and E. Wieschaus. 1980. Mutations affecting segment number and polarity in Drosophila. Nature 287: 795-801.

Nüsslein-Volhard, C., E. Wieschaus, and H. Kluding. 1984. Mutations affecting the pattern of the larval cuticle in Drosophila melanogaster. I. Zygotic loci on the second chromosome. Wilhem Roux's Arch. Dev. Biol. 193: 267-282.

Orenic, T., J. Chidsey, and R. Holmgren 1987. Cell and cubitus interruptus Dominant: Two segment polarity genes on the fourth chromosome in Drosophila. Dev. Biol. 124: 50-56.

Patel, N.H., P.M. Snow, and C.S. Goodman. 1987. Characterization and cloning of fasciclin III: A glycoprotein expressed on a subset of neurons and axon pathways in Drosophila. Cell 48: 975-988.

Perrimon, N. and A.P. Mahowald. 1987. Multiple functions of segment polarity genes in Drosophila. Dev. Biol. 119: 587600.

Rijsewijk, F., M. Schuermann, C. Wagenaar, P. Parren, D. Weigel, and R. Nusse. 1987.The Drosophila homolog of the mouse mammary oncogene int 1 is identical to the segment polarity gene wingless. Cell 50: 649-657.

Snow, P.M., N.H. Patel, A.L. Harrelson, and C.S Goodman. 1987. Neural-specific carbohydrate moiety shared by many surface glycoproteins in Drosophila and grasshopper embryos. J. Neurosci. 7: 4137-4144.

Taghert, P.H. and C.S. Goodman. 1984. Cell determination and differentiation of identified serotonin-immunoreactive neurons in the grasshopper embryo. I. Neuroscience 4: 9891000.

Valles, A. and K. White. 1985. Serotonergic Cells in Drosophila. Soc. Neurosci. Abstr. 11: 958 .

Wieschaus, E. and E. Noell. 1986. Specificity of embryonic lethal mutations in Drosophila analyzed in germ line clones. Wilhelm Roux's Arch. Dev. Biol. 195: 63-73.

Wieschaus, E., C. Nüsslein-Volhard, and G. Jürgens. 1984. Mutations affecting the pattern of the larval cuticle in Drosophila melanogaster. III. Zygotic loci on the X chromosome and the fourth chromosome. Wilhem Roux's Arch. Dev. Biol. 193: 296-307. 


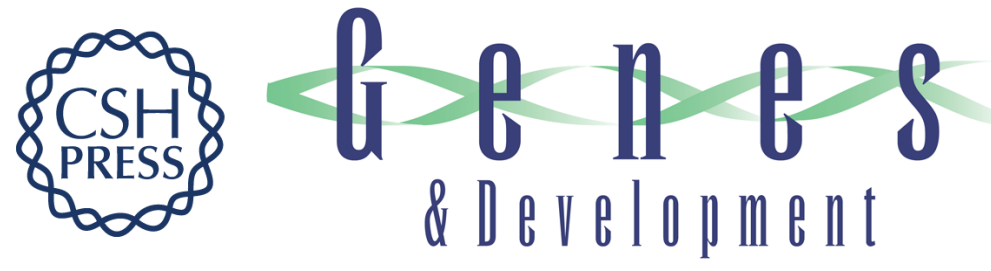

\section{The role of segment polarity genes during Drosophila neurogenesis.}

N H Patel, B Schafer, C S Goodman, et al.

Genes Dev. 1989, 3:

Access the most recent version at doi:10.1101/gad.3.6.890 $\begin{array}{ll}\text { References } & \begin{array}{l}\text { This article cites } 42 \text { articles, } 9 \text { of which can be accessed free at: } \\ \text { http://genesdev.cshlp.org/content/3/6/890.full.html\#ref-list-1 }\end{array}\end{array}$

License

Email Alerting Service

Receive free email alerts when new articles cite this article - sign up in the box at the top right corner of the article or click here.

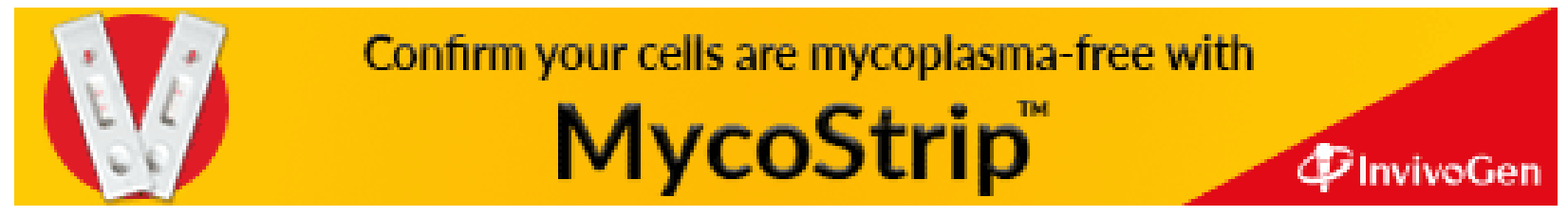

